\title{
La propuesta de ciudadanía radical y las representaciones sociales de estudiantes de bachillerato en Colombia
}

\author{
The radical citizenship proposal and the \\ social representations of high school students in Colombia \\ Luis Felipe Caballero Dávila ${ }^{\mathrm{a}}$, Gustavo González Valencia ${ }^{\mathrm{b}}$ \& \\ ANTONI SANTISTEBAN FERNÁNDEZ ${ }^{\mathrm{C}}$ \\ asecretaría de Educación de Bogotá, Bogotá, Colombia. \lufecada@hotmail.com \\ [orcid.org/0000-0001-6042-679X] \\ b Universitat Autònoma de Barcelona, Barcelona, España. gustavo.gonzález@uab.cat \\ [orcid.org/0000-0001-8718-417X] \\ 'Universitat Autònoma de Barcelona, Barcelona, España. antoni.santisteban@uab.cat \\ [orcid.org/0000-0001-7978-5186]
}

\section{RESUMEN}

Este artículo presenta los resultados de una investigación acerca de las representaciones sociales que tienen estudiantes de la educación media (16 a 18 años) en Colombia acerca de la ciudadanía, la democracia, la participación y la política. El abordaje teórico del trabajo reconoció, como punto de partida, 4 modelos teóricos: el liberal, el republicano, el comunitarista y el radical. El trabajo se enmarcó en la perspectiva del núcleo central y el sistema periférico. La metodología del estudio fue mixta. La información fue obtenida a través de un cuestionario de preguntas abiertas y cerradas. Los hallazgos muestran que los estudiantes tienen unas representaciones que se ubican entre los modelos liberal y republicano. La identificación del núcleo central de las representaciones permite el diseño de propuestas didácticas que superen los discursos hegemónicos de las categorías estudiadas y contribuyan a la construcción de un futuro con mayor justicia social.

PALABRAS CLAVE: Educación para la ciudadanía, ciudadanía radical, propuestas didácticas.

\section{ABSTRACT}

This article presents the results of an investigation about the social representations of high school students (16 to 18 years old) in Colombia regarding citizenship, democracy, participation and politics. The theoretical approach to the work recognized, as a starting point, 4 theoretical models: the liberal, the republican, the communitarian and the radical. 


\section{F. CABAlLero et al.}

The work was framed in the perspective of the central nucleus and the peripheral system. The study methodology was mixed. The information was obtained through a questionnaire of open and closed questions. The findings show that the students have representations that fall between the liberal and republican models. The identification of the central nucleus of the representations allows the design of didactic proposals that go beyond the hegemonic discourses of the studied categories and contribute to the construction of a future with greater social justice.

KEY WORDS: Education for citizenship, radical citizenship, didactic proposals.

\section{INTRODUCCIÓN}

En Colombia, entre el año 1990 y el 2000, con la nueva constitución y distintas leyes, decretos y estándares se dio un avance jurídico en la formación en derechos humanos, paz y democracia. Sin embargo, lo anterior no ha implicado que se promueva una cultura de la participación ciudadana y se asuma la ciudadanía desde una posición crítica y participativa. Algunos estudios (Herrera et al. 2005; Pinilla \& Torres, 2006; González-Valencia \& Santisteban, 2016) señalan que, en el país y en la escuela, las ideas de ciudadanía, democracia y participación se han limitado a los procesos democráticos representativos, deliberativos y parlamentarios no directos (elecciones y voto), en donde la ciudadanía tiene un papel pasivo en la construcción democrática. Así, los procesos democráticos se han instrumentalizado y no permiten las transformaciones de las estructuras sociales de poder y del orden hegemónico.

Con la Constitución de 1991 y el Decreto 1860 de 1994, se da un avance jurídico para promover la participación de la comunidad estudiantil y la democratización de la escuela con la elección de los gobiernos escolares en las instituciones educativas. No obstante, una gran cantidad de estudios (Cubides, 2000; Álvarez \& Monedero, 2002; Pinilla \& Torres, 2006; Jiménez, 2014; Rodríguez \& Contreras, 2014; Caballero, 2015; Rivera, 2016), que indagan sobre la relación que existe entre el proyecto de Gobierno Escolar y la promoción de la Democracia y la participación de los estudiantes en la escuela, llegan a la conclusión de que este tipo de ejercicio ha llevado a que los estudiantes instrumentalicen el ejercicio participativo y democrático, y lo asocien a una democracia representativa, que sólo implica votar y elegir a los representantes, sin tomar responsabilidad en otros tipos de participación social o política.

Las situaciones descritas legitiman las relaciones jerárquicas horizontales, en donde un grupo reducido de personas son las que terminan debatiendo y decidiendo el porvenir de toda la comunidad educativa. Igualmente, estos estudios (Cubides, 2000; Álvarez \& Monedero, 2002; Pinilla \& Torres, 2006; Jiménez, 2014; Rodríguez \& Contreras, 2014; Caballero, 2015; Rivera, 2016) señalan que las figuras del Personero Estudiantil y de los Representantes Estudiantiles se han desgastado y han ido perdiendo credibilidad y legitimidad. Esto, debido a su poca incidencia en las decisiones sobre aspectos pedagógicos, presupuestales y de convivencia que se toman en la escuela, olvidando que ésta debe ser un ámbito de experiencia en la participación y en el ejercicio de la ciudadanía. 
En cuanto a las representaciones sociales (RS), Rivera (2016) señala que la instrumentalización de los procesos democráticos ha llevado a que se dé un alto grado de desafección frente al desarrollo y los resultados de la democracia liberal, porque no se ha favorecido la construcción de un orden social más justo. Lo anterior ha derivado en una cultura de la compra y venta del voto, los favores políticos, etc., lo que lleva a que se perpetúe un sistema electoral corrupto y fragmentado, con campañas políticas cimentadas en el intercambio económico individual (clientelismo). El contexto presentado nos llevó a preguntarnos: ¿Cuáles son las RS de los estudiantes en relación a la política, la participación, la ciudadanía y la democracia? ¿Qué tipo de intervención didáctica se puede desarrollar para cuestionar las RS que tienen los estudiantes de la política, la participación, la ciudadanía y la democracia, generando cambios en la línea de una ciudadanía crítica, participativa y radical?

\section{APROXIMACIONES TEÓRICAS. MODELOS DE CIUDADANÍA Y LAS REPRESENTACIONES SOCIALES}

\section{Modelos de política, participación, ciudadanía y democracia}

En lo referente a la política, la participación, la ciudadanía y la democracia distinguiremos, a partir de distintos autores (Cortina, 1997; Peña, 2000; Cerda et al. 2004; Jaime, 2008; Benedicto, 2008; Santisteban \& Pagès, 2009; González-Valencia, 2009; Horrach, 2009; Muñoz et al. 2010; Sant \& Pagès, 2012; De Alba \& Navarro, 2016; Salinas \& Oller, 2017), cuatro modelos: el liberal, el comunitarista (Kymlicka \& Norman, 1997), el republicano (Arendt, 1997; Habermas, 1997) y el radical (Ranciere, 2006; Mouffe, 2007), los cuales se diferencian en la forma en que asumen la política, entienden la democracia, conciben los derechos y los deberes y ejercen la participación; poniendo el énfasis en algún aspecto de la ciudadanía (pertenencia, derechos o participación). Ciudadanía que se entiende como una forma de participación (derecho a la palabra y forma de acción) y de pertenencia y como el hecho de poseer y adherirse a unos derechos (civiles, políticos y sociales), deberes y a una concepción de justicia. La tabla 1 sintetiza los atributos característicos de los cuatro modelos.

En términos teóricos proponemos que es importante que las instituciones educativas desarrollen en los estudiantes la posibilidad de ejercer una participación y una ciudadanía crítica, radical y directa, en donde sean conscientes de su realidad social, críticos frente al pasado, capaces de formular cambios del sistema capitalista a nivel estructural, comprometidos con la transformación de su entorno (De Alba \& Navarro, 2016) y que tengan el potencial de resistir, cuestionar, incidir directamente en las decisiones políticas y transformar el orden social, donde la política no busque erradicar las diferencias ni el conflicto a través del consenso, sino que permita la existencia legítima de todas las posiciones enfrentadas, lo que conocemos como agonismo, el cual defiende la existencia permanente del conflicto y la lucha por el poder, llevando a mirar al otro no como enemigo sino como adversario (Mouffe, 2007). Igualmente, concebimos esta forma de participación y de ciudadanía como 


\section{F. Caballero et al.}

Tabla 1. Modelos de política, democracia, participación y ciudadanía.

\begin{tabular}{|c|c|c|c|c|}
\hline Características & Liberal & Republicano & Comunitarista & Radical \\
\hline $\begin{array}{l}\text { ¿Cómo } \\
\text { asumen la } \\
\text { política? }\end{array}$ & $\begin{array}{l}\text { Es la elaboración de } \\
\text { leyes y derechos, la } \\
\text { representatividad, la } \\
\text { administración y la } \\
\text { regulación social }\end{array}$ & $\begin{array}{l}\text { Es la asamblea } \\
\text { y el parlamento, } \\
\text { en donde todos } \\
\text { debaten, se } \\
\text { refutan, deliberan } \\
\text { en pluralidad } \\
\text { y a través de } \\
\text { la palabra se } \\
\text { persuaden entre sí }\end{array}$ & $\begin{array}{l}\text { Es el colectivo, } \\
\text { la pertenencia, } \\
\text { la identidad, el } \\
\text { autogobierno y } \\
\text { la búsqueda del } \\
\text { reconocimiento }\end{array}$ & $\begin{array}{c}\text { Es la capacidad de } \\
\text { cuestionar la autoridad, } \\
\text { recusar las posiciones y } \\
\text { lugares asignados desde } \\
\text { la institucionalidad, } \\
\text { oponerse, ejercer la } \\
\text { crítica, acoger las } \\
\text { causas del otro, resistir, } \\
\text { emanciparse, disputar } \\
\text { espacios y transformar la } \\
\text { sociedad }\end{array}$ \\
\hline $\begin{array}{c}\text { ¿Cómo } \\
\text { entienden la } \\
\text { democracia? }\end{array}$ & $\begin{array}{l}\text { La limitan al hecho } \\
\text { representativo y a los } \\
\text { procesos de elección } \\
\text { de gobernantes y } \\
\text { representantes }\end{array}$ & $\begin{array}{l}\text { Como un diálogo } \\
\text { reflexivo y } \\
\text { racional entre los } \\
\text { ciudadanos y sus } \\
\text { representantes }\end{array}$ & $\begin{array}{c}\text { De una forma } \\
\text { participativa y } \\
\text { desde instituciones } \\
\text { democráticas locales/ } \\
\text { Se construye desde } \\
\text { la pertenencia de los } \\
\text { sujetos y desde el } \\
\text { sentir colectivo (la } \\
\text { toma colectiva de } \\
\text { decisiones) }\end{array}$ & $\begin{array}{c}\text { Es el conflicto, el } \\
\text { desacuerdo, la disputa y } \\
\text { la generación de espacios } \\
\text { legítimos de acción y } \\
\text { participación para la } \\
\text { oposición/Defiende la } \\
\text { participación popular } \\
\text { directa y el protagonismo } \\
\text { de las personas y } \\
\text { colectivos invisibilizados, } \\
\text { marginados y excluidos }\end{array}$ \\
\hline $\begin{array}{l}\text { ¿Cómo } \\
\text { conciben los } \\
\text { derechos? }\end{array}$ & $\begin{array}{l}\text { Se ganan por medio de } \\
\text { méritos y la iniciativa } \\
\text { individual, por lo } \\
\text { cual hay que cumplir } \\
\text { con las obligaciones } \\
\text { y responsabilidades } \\
\text { sin cuestionarlas / } \\
\text { Los derechos y } \\
\text { las libertades son } \\
\text { individuales }\end{array}$ & $\begin{array}{l}\text { Los derechos son } \\
\text { la garantía de } \\
\text { unas condiciones } \\
\text { básicas para poder } \\
\text { participar }\end{array}$ & $\begin{array}{c}\text { Deben darse } \\
\text { derechos y políticas } \\
\text { diferenciadas para } \\
\text { las comunidades } \\
\text { minoritarias } \\
\text { y oprimidas y } \\
\text { deben basarse en } \\
\text { la solidaridad/ } \\
\text { Los derechos son } \\
\text { colectivos }\end{array}$ & $\begin{array}{c}\text { Los derechos deben } \\
\text { otorgarse en igualdad, } \\
\text { sin distingo de grupos o } \\
\text { condiciones históricas, } \\
\text { sociales, económicas o } \\
\text { culturales y son la base } \\
\text { de las demandas para } \\
\text { la cohesión social y la } \\
\text { emancipación }\end{array}$ \\
\hline $\begin{array}{c}\text { ¿En qué } \\
\text { aspecto de la } \\
\text { ciudadanía } \\
\text { ponen énfasis? }\end{array}$ & $\begin{array}{c}\text { En los deberes y } \\
\text { derechos individuales, } \\
\text { fundamentándose en } \\
\text { la no injerencia del } \\
\text { Estado y primando: } \\
\text { el bien individual } \\
\text { sobre el bien común, } \\
\text { la voluntad soberana } \\
\text { del individuo, la } \\
\text { ley, la concepción } \\
\text { instrumental de los } \\
\text { derechos políticos y } \\
\text { el otorgamiento de la } \\
\text { representación de los } \\
\text { intereses particulares } \\
\text { a una élite política de } \\
\text { profesionales }\end{array}$ & $\begin{array}{c}\text { En la participación } \\
\text { activa e } \\
\text { institucional, } \\
\text { fundamentada } \\
\text { en el diálogo y } \\
\text { la deliberación } \\
\text { pública }\end{array}$ & $\begin{array}{l}\text { En la pertenencia, } \\
\text { priorizando la } \\
\text { vida comunitaria, } \\
\text { el bien común, el } \\
\text { consenso grupal, la } \\
\text { participación activa y } \\
\text { compromiso mutuo } \\
\text { al servicio de la } \\
\text { identidad colectiva } \\
\text { y las razones de } \\
\text { la comunidad. } \\
\text { Comunidad en donde } \\
\text { el individuo haya su } \\
\text { autorrealización }\end{array}$ & $\begin{array}{l}\text { En la justicia social/ las } \\
\text { personas luchan y se } \\
\text { comprometen con el bien } \\
\text { común, desde la identidad } \\
\text { y la pertenencia a distintos } \\
\text { grupos, apuntando a } \\
\text { la construcción de un } \\
\text { nosotros que incluye las } \\
\text { exigencias de distintos } \\
\text { movimientos/ En el } \\
\text { compromiso de construir } \\
\text { una sociedad más justa, } \\
\text { equitativa e igualitaria, } \\
\text { participando activamente } \\
\text { en los proyectos y } \\
\text { experiencias de la } \\
\text { comunidad }\end{array}$ \\
\hline
\end{tabular}




\begin{tabular}{|c|c|c|c|c|}
\hline \multirow[t]{3}{*}{$\begin{array}{c}\text { ¿Cómo } \\
\text { ejercen la } \\
\text { participación } \\
\text { ciudadana? }\end{array}$} & $\begin{array}{l}\text { De forma pasiva y a } \\
\text { través del voto, los } \\
\text { procesos electorales, } \\
\text { el contacto con los } \\
\text { políticos, afiliándose } \\
\text { y colaborando con } \\
\text { los partidos políticos, } \\
\text { donando dinero, } \\
\text { informándose sobre } \\
\text { temas políticos a } \\
\text { través de los medios } \\
\text { de comunicación } \\
\text { y respetando los } \\
\text { representantes } \\
\text { políticos/Son poco o } \\
\text { nada comprometidos } \\
\text { con la realidad social } \\
\text { y los problemas que } \\
\text { los rodean y tienen } \\
\text { poca iniciativa y } \\
\text { opiniones genéricas, } \\
\text { ambiguas, poco } \\
\text { elaboradas y } \\
\text { argumentadas, por } \\
\text { lo que no proponen } \\
\text { soluciones ni plantean } \\
\text { cambios al modelo } \\
\text { socioeconómico }\end{array}$ & $\begin{array}{l}\text { A través de la } \\
\text { opinión, dando } \\
\text { a conocer su } \\
\text { posicionamiento } \\
\text { ante una situación } \\
\text { por medio } \\
\text { del diálogo, la } \\
\text { argumentación, la } \\
\text { razón, el debate, } \\
\text { el parlamento, } \\
\text { la conciliación y } \\
\text { la participación } \\
\text { en discusiones } \\
\text { políticas y } \\
\text { utilizando los } \\
\text { procedimientos } \\
\text { establecidos } \\
\text { institucionalmente } \\
\text { y que están } \\
\text { orientados por } \\
\text { las élites/Tienen } \\
\text { una actitud } \\
\text { comprometida } \\
\text { y una opinión } \\
\text { formada sobre los } \\
\text { problemas, pero } \\
\text { no son capaces de } \\
\text { establecer otros } \\
\text { modelos o dar } \\
\text { características } \\
\text { concretas de un } \\
\text { cambio. }\end{array}$ & $\begin{array}{l}\text { De forma asociativa, } \\
\text { directa y activa y } \\
\text { para el servicio del } \\
\text { colectivo y el bien } \\
\text { común/Realizando } \\
\text { y siendo parte } \\
\text { de actividades } \\
\text { de beneficio para } \\
\text { la comunidad, } \\
\text { trabajando en equipo } \\
\text { y cooperando }\end{array}$ & $\begin{array}{c}\text { A través de acciones no } \\
\text { convencionales, como: } \\
\text { desarrollar campañas } \\
\text { sociales y políticas, la } \\
\text { organización, la protesta, } \\
\text { el boicot, reivindicación } \\
\text { de espacios para } \\
\text { la comunidad, la } \\
\text { manifestación, la huelga } \\
\text { y la movilización social. } \\
\text { Buscando el cambio del } \\
\text { gobierno y proponiendo } \\
\text { soluciones y alternativas } \\
\text { a los problemas/Utilizan } \\
\text { formas de participación, } \\
\text { no dirigidas ni reguladas } \\
\text { institucionalmente, } \\
\text { las cuales desafían } \\
\text { directamente a las } \\
\text { élites/Son conscientes } \\
\text { de la realidad, tienen } \\
\text { una actitud declarada } \\
\text { de compromiso y son } \\
\text { capaces de formular } \\
\text { cambios a nivel } \\
\text { estructural }\end{array}$ \\
\hline & Participación electoral & $\begin{array}{l}\text { Participación } \\
\text { institucional }\end{array}$ & $\begin{array}{l}\text { Participación } \\
\text { comunitaria }\end{array}$ & $\begin{array}{l}\text { Participación para la } \\
\text { transformación social }\end{array}$ \\
\hline & Convenc & onal & No co & vencional \\
\hline
\end{tabular}

Fuente: Elaboración propia.

un proceso de emancipación, a través del cual se cuestionan las posiciones y lugares que nos han sido asignados por el orden hegemónico, poniendo en crisis las RS propias y permitiendo la posibilidad de identificación con las causas del otro (Ranciere, 2006).

De esta manera, queremos que los estudiantes participen y ejerzan su ciudadanía a través de acciones que están vinculadas al desacuerdo y que trascienden las maneras convencionales de hacer política, proponiendo la asociación, las protestas, la manifestación, la movilización social y el agonismo (Mouffe, 2007), poniendo en cuestión y transformando la hegemonía opresiva y socialmente injusta (Ross \& Vinson, 2012), las concepciones de lo público y lo privado, las restricciones de lo que puede o no puede decirse, las posiciones y formas institucionales de estar juntos (Ranciere, 2006) y las RS hegemónicas de la política, la participación, la ciudadanía y la democracia. 


\section{F. Caballero et al.}

\section{Las representaciones sociales}

Los estudios sobre RS buscan develar el trasfondo ideológico que hay detrás de las acciones de las personas (González-Valencia, 2012). En el presente artículo consideramos importante indagar las RS que tienen los estudiantes sobre la política, la participación, la democracia y la ciudadanía, pues éstas se verán reflejadas en las posiciones y acciones que asumen y toman frente al sistema político, las cuestiones públicas, las relaciones de poder, las instituciones políticas y la democracia.

La investigación asumió las RS, desde distintos autores (Moscovici, 1961; Jodelet, 1984; Araya, 2002; Pagès \& Oller, 2007; Lautier como se citó en Sant et al. 2011), como las imágenes, conocimientos, ideas, concepciones y saberes que tienen los sujetos de las personas, instituciones, objetos y prácticas y la forma en que las clasifican, evalúan y explican. Teniendo en cuenta que las RS incorporan opiniones, estereotipos, creencias, valores y normas.

En la teoría de las RS existen diferentes perspectivas teóricas, la asumida por la investigación será la teoría del Núcleo Central (NC) (Abric, 2001). Ésta plantea que las RS están constituidas por un conjunto de informaciones, creencias, opiniones y actitudes organizadas y estructuradas alrededor de un NC, el cual está formado por uno o varios elementos que organizan y determinan la significación de la representación (Abric, 2001).

Desde la perspectiva del NC, el análisis de una RS y la comprensión de su funcionamiento requiere la identificación y comprensión de su contenido y estructura, pues los elementos que la integran son jerarquizados, asignados y mantienen una relación entre ellos. Relación que determina la connotación y el lugar que ocupan en el sistema representacional (Abric, 2001). De esta manera, según esta perspectiva, el NC se compone por los elementos y significados más compartidos y estables de las representaciones (las RS hegemónicas).

En cuanto al sistema periférico (SP), alrededor del NC se ubican elementos periféricos que ilustran, aclaran y justifican la significación. Elementos que son más flexibles y expresan el anclaje de las RS a contextos y perspectivas sociales particulares y posicionamientos diferenciales (Abric, 2001; Abric como se citó en Bruno \& Barreiro, 2015).

En suma, las RS están integradas por un NC y un SP. Pensamos, entonces, que encontrando el NC y los elementos periféricos (SP) de las RS de la política, la participación, la democracia y la ciudadanía de los estudiantes, podremos diseñar intervenciones didácticas que tengan una mayor posibilidad de generar transformaciones y cuestionar las RS Hegemónicas en la línea de una Ciudadanía crítica, participativa y radical.

\section{METODOLOGÍA DE LA INVESTIGACIÓN}

En términos metodológicos, la investigación del presente artículo fue de carácter mixta, pues se empleó una aproximación cuantitativa y cualitativa con la que se indagó en el pensamiento del alumnado sobre los conceptos asociados a la política, la participación, la democracia y la ciudadanía. Todo esto con la finalidad de comprender cómo entienden 
su mundo y construyen las RS que guían sus formas de participar y de ser ciudadanos. En el presente trabajo, se planteó un estudio de caso, con el fin de generar unas orientaciones didácticas enmarcadas en el paradigma crítico (Benejam, 1997).

Para la recolección de la información se utilizó un cuestionario que incluye la técnica de la asociación de palabras a partir de los términos inductores: ciudadanía, participación, política y democracia. Con esto se indagó por palabras, expresiones, acciones y personas que los estudiantes asocian semánticamente a cada término. Igualmente, se les preguntó por las formas de participar que han ejercido y que ejercerían en determinados momentos y por los principales temas que se les enseñan en las clases de ciencias sociales sobre participación, democracia, política y ciudadanía ${ }^{1}$. El cuestionario se realizó de manera virtual a un grupo de 15 estudiantes del último curso de bachillerato de una escuela pública de la localidad de Suba-Tibabuyes en Bogotá-Colombia², seleccionados a través de un muestreo intencional ${ }^{3}$.

Los estudiantes que realizaron el cuestionario pertenecen, la mayoría, a los estratos socio-económicos más humildes (93,3\%), sus padres se dedican a oficios de baja cualificación (construcción, comercio, transporte, vigilancia, servicio doméstico y cuidado), y al empleo informal. El nivel educativo de sus padres y hermanos se encuentra entre primaria y bachillerato (alrededor del 67\%) y la mayoría fueron mujeres $(66,7 \%)$ con edades comprendidas entre los 17 y los 18 años (80\%).

Para deducir el contenido y las características de las RS de ciudadanía de los estudiantes se realizó un análisis de tipo estadístico descriptivo de los datos, a través de tres procedimientos: primero, la frecuencia de las palabras, es decir, el número de veces que aparece la palabra (Abric, 2001a; Araya, 2002; Bruno \& Barreiro, 2015); segundo, el número de veces que aparece la palabra en primer lugar (Abric, 2001a; Araya, 2002; Bruno \& Barreiro, 2015); y tercero, el modelo de política, participación, ciudadanía y democracia con el cual se relacionan las palabras. Estas RS de la política, la participación, la ciudadanía y la democracia a su vez se relacionarán con las formas en que han ejercido o ejercerían su participación y la forma en que se les han enseñado la participación en las clases de ciencias sociales.

\section{LAS RS DE LA POLÍTICA, LA DEMOCRACIA, LA PARTICIPACIÓN Y LA CIUDADANÍA}

Teniendo en cuenta la teoría del NC (Abric, 2011), es importante descifrar el NC de la RS de la Política, la Ciudadanía, la Democracia y la Participación que tienen los estudiantes y la manera en que se las ha enseñado en las clases de ciencias sociales, para poder desarrollar

1 Para mirar el cuestionario y los resultados ingresar a: https://forms.gle/vS3d6sFXV2YuP6tQA

2 Según los datos de integración social, la zona de Suba-Tibabuyes se caracteriza por ser una zona de recepción de migración y de autogestión y construcción de los barrios, evidenciándose “condiciones de precariedad, familias extensas, bajos recursos económicos y niveles bajos de educación (...) La situación apremiante del conjunto de familias y personas en el territorio hace que las medidas de política pública no sean suficientes y efectivas a la hora de incidir en estas condiciones” (Alcaldía de Bogotá, 2015).

3 Los estudiantes fueron elegidos por ser parte del colegio en el cual uno de los autores se desempeña como docente. Población que se busca impactar con la investigación. La muestra se compone por 15 estudiantes (el 60\%) del último curso del año 2019. 


\section{F. CABAlLero et al.}

una propuesta de intervención didáctica que ayude a presentar una propuesta de ciudadanía radical y que permita comprender las formas de participación que han ejercido y ejercerían en distintas situaciones.

\section{Las RS de la Política}

Por medio de la técnica de asociación de palabras se obtuvieron 122. Para estudiar la estructura de las RS, las palabras fueron agrupadas según su relación con los distintos modelos de política (Tabla 2) y, como la política parece despertar tantas emociones, también se agruparon algunos términos según el sentido de la expresión, palabra o emoción en: negativas y positivas. Por lo cual, el corpus textual se redujo a un total de 45 (no todas las palabras de la Tabla 2 fueron asociadas). Las palabras que fueron difíciles de relacionar en algún modelo, por su carácter general y ambiguo, se agruparon según las otras palabras que vincularon los estudiantes con el concepto de política.

Tabla 2. RS y Modelos de política: ¿Qué palabras asocian?

\begin{tabular}{|c|c|c|c|c|}
\hline Características & Liberal & Republicano & Comunitarista & Radical \\
\hline $\begin{array}{c}\text { ¿Qué palabras } \\
\text { asocian con la } \\
\text { política? }\end{array}$ & $\begin{array}{l}\text { Leyes, derechos, } \\
\text { Estado, Gobiernos, } \\
\text { Políticos, Partidos } \\
\text { Políticos, normas } \\
\text { responsabilidad, } \\
\text { Constitución. }\end{array}$ & $\begin{array}{l}\text { Parlamento, } \\
\text { opinión, discusión, } \\
\text { refutación, } \\
\text { reflexión, } \\
\text { persuasión, } \\
\text { pluralidad, } \\
\text { acuerdos, consenso }\end{array}$ & $\begin{array}{c}\text { Pertenencia, } \\
\text { identidad, } \\
\text { asociación y } \\
\text { reconocimiento }\end{array}$ & $\begin{array}{l}\text { Empoderamiento, } \\
\text { Liderazgo, creación, } \\
\text { futuro, Autonomía, } \\
\text { Solidaridad, Derechos } \\
\text { Humanos, cuestionar, } \\
\text { oponerse, crítica, } \\
\text { libertad, solidaridad, } \\
\text { transformación, justicia } \\
\text { social, resistencia, } \\
\text { adversario y disputa }\end{array}$ \\
\hline
\end{tabular}

Fuente: Elaboración propia.

Como lo muestra la Fig. 1 las palabras que aparecieron con mayor frecuencia están relacionadas con un modelo de política liberal $(57,3 \%)$. Los términos más comunes fueron: políticos o personajes políticos, gobernantes, democracia, gobierno y derechos. Por otro lado, los estudiantes también relacionaron la política, principalmente, con las palabras debate y toma de decisiones, lo que se puede asociar con el modelo de política republicano (23,2\%). Otros términos que asociaron los estudiantes de forma mayoritaria y que no podemos relacionar con alguno de los modelos, pero que son prueba de la visión negativa que se tiene de la política, fueron: corrupción, mentiras e injusticias.

En un primer momento, al preguntarles a los estudiantes por el sentimiento que les produce la política, el 53.3\% expresa que entusiasmo e interés y el $40 \%$ que desconfianza e indiferencia. De lo cual podemos deducir que el interés de los estudiantes por la política se encuentra dividido. Sin embargo, cuando se trata de una participación activa, sólo el 20\% se considera políticamente comprometido, mientras que el 60\% de los estudiantes expresa estar enterado de la política, pero no participar de manera activa de ella y el 20\% de los estudiantes afirma que la política no le interesa, que no suelen estar muy informados o que sólo intentan estar al corriente de ella. 
FORMACIÓN CIUDADANA Y REPRESENTACIONES SOCIALES

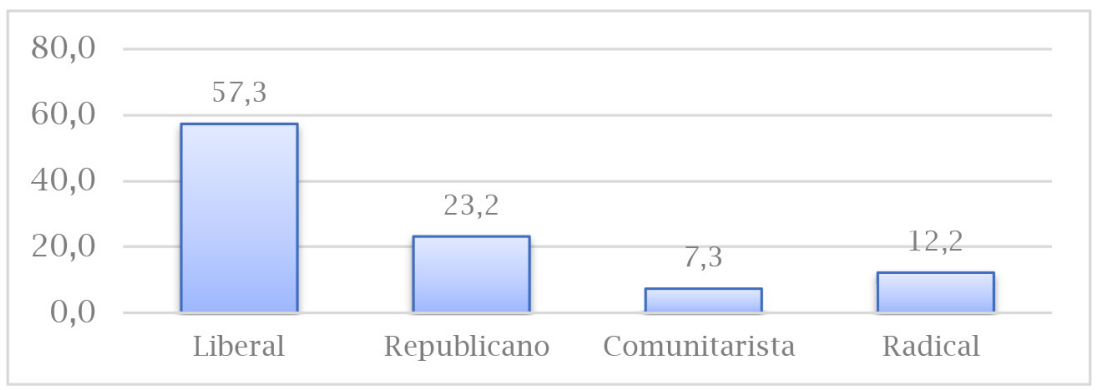

Fig. 1. Frecuencia de palabras según modelos de política. Fuente: Elaboración propia.

De la misma manera, a pesar de que el interés por la política parece estar dividido, al preguntarles a los estudiantes por las palabras que asocian a la política y, que se pueden clasificar como sentimientos, emociones, opiniones o expresiones negativas o positivas, el 69\% fueron términos negativos (Fig. 2). Las palabras que más asociaron con la política fueron: corrupción, mentiras e injusticias.

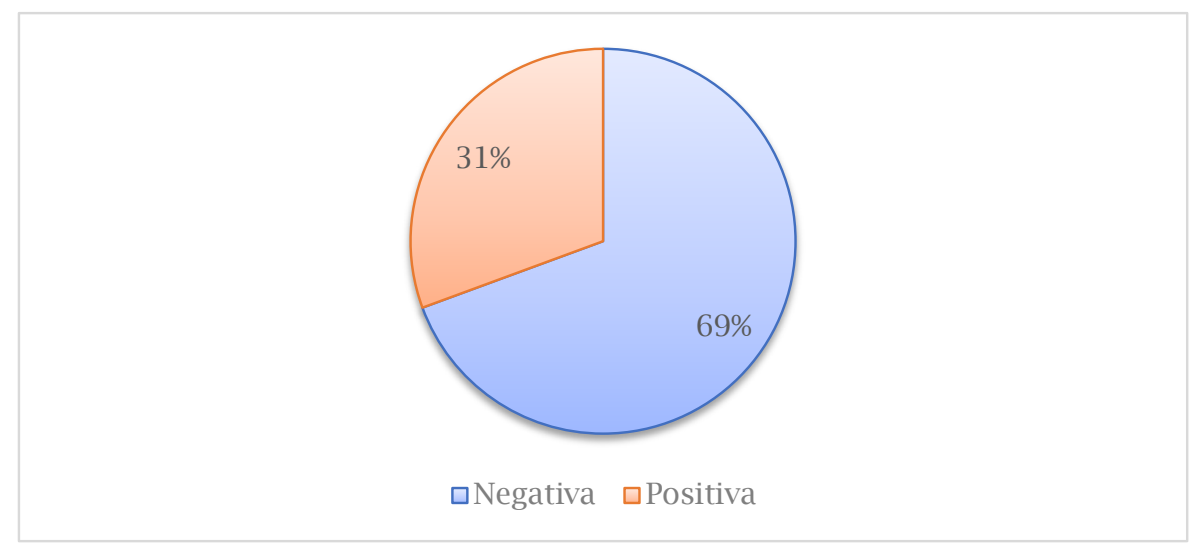

Fig. 2. Frecuencia de palabras según la visión de la política.

Fuente: elaboración propia.

Las palabras que más se asociaron con la política fueron: políticos, corrupción, debate, mentiras, gobernantes y democracia. Éstas aparecieron un total de 50 veces, es decir que son el 41\% del corpus textual y un total de 6 de los 15 estudiantes, es decir, el 40\% de los participantes, asoció en primer lugar la palabra corrupción con la política. Lo anterior nos sugirió que el NC de la RS de la política, para este grupo, está compuesto por aspectos como: políticos y corrupción, por lo cual, podríamos deducir que los estudiantes se representan a la política como un grupo de personas corruptas que se dedican a la política.

Teniendo en cuenta estos resultados, evidenciamos que la principal característica y contenido de las RS de la política de los estudiantes están asociados a una visión negativa del ejercicio de la política; ejercicio que se representa desde un modelo de política liberal, en donde se da un ejercicio representativo de participación ciudadana, en el cual se eligen unos 


\section{F. CABAllero et al.}

representantes políticos que, por lo general, son corruptos y deshonestos, según la visión de los estudiantes. En otras palabras, los estudiantes no han asumido que la política también la ejerce el pueblo y la puede ejercer de forma directa, crítica y radical.

\section{Las RS de la Democracia}

A través de la técnica de asociación de palabras se obtuvieron 56. Para estudiar la estructura de la RS, las palabras fueron agrupadas según su relación con los distintos modelos de democracia (Tabla 3). Por lo cual, el corpus textual se redujo a un total de 24 (no todas las palabras de la Tabla 3 fueron asociadas). Las palabras que fueron difíciles de relacionar en algún modelo, por su carácter general y ambiguo, se agruparon según las otras palabras que vincularon los estudiantes con el concepto de democracia.

Tabla 3. RS y Modelos de democracia: ¿Qué palabras asocian?

\begin{tabular}{|c|c|c|c|c|}
\hline Características & Liberal & Republicano & Comunitarista & Radical \\
\hline $\begin{array}{c}\text { ¿Qué palabras } \\
\text { asocian con la } \\
\text { democracia? }\end{array}$ & $\begin{array}{c}\text { Forma de gobierno, } \\
\text { manera de } \\
\text { llegar al poder, } \\
\text { Representación, } \\
\text { elecciones y voto }\end{array}$ & $\begin{array}{c}\text { Diálogo, razón, } \\
\text { asamblea, } \\
\text { argumentos, debate }\end{array}$ & $\begin{array}{l}\text { Identidad, } \\
\text { pertenencia, } \\
\text { grupo, colectivo, } \\
\text { comunidad y } \\
\text { minorías }\end{array}$ & $\begin{array}{l}\text { Desacuerdo, oposición, } \\
\text { crítica, libertad y lucha. }\end{array}$ \\
\hline
\end{tabular}

Fuente: Elaboración propia.

Como lo muestra la Fig. 3, las palabras que aparecieron con mayor frecuencia están relacionadas con un modelo democrático liberal y representativo (58,5\%). Los términos más comunes fueron: personajes políticos e históricos, votar, sistema o régimen. Por otro lado, los estudiantes también relacionaron la democracia, principalmente, con las palabras igualdad y pueblo, lo que se puede asociar con el modelo democrático radical $(18,9 \%)$ y comunitarista (17\%).

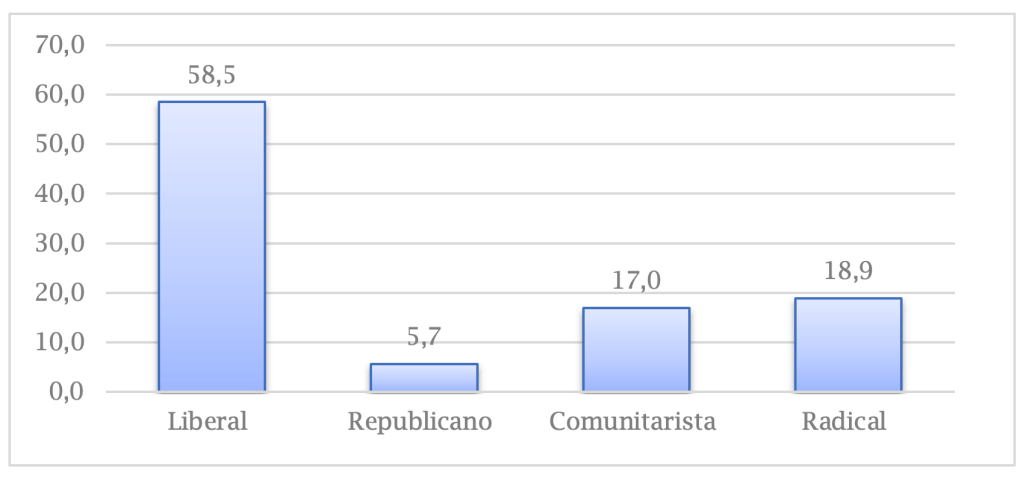

Fig. 3. Frecuencia de palabras según modelos de democracia. Fuente: Elaboración propia.

Las palabras que más asociaron con la democracia fueron: personajes políticos o históricos, votar, pueblo e igualdad. Éstas aparecieron un total de 32 veces, es decir que son el 57\% del corpus textual. Un total de 8 de los 15 estudiantes, es decir, el 53\% de los participantes, asoció, en primer lugar, una palabra relacionada con la democracia liberal y 
representativa. Lo anterior nos sugirió que el NC de la RS de la democracia, para este grupo, está compuesto por aspectos como: políticos y elecciones, por lo cual, podríamos deducir que los estudiantes se representan la democracia como un sistema o régimen político en el cual hay igualdad política y en donde el pueblo elige sus representantes y gobernantes de entre una élite política.

Teniendo en cuenta estos resultados, evidenciamos que las principales características y contenidos de las RS de la democracia de los estudiantes están asociados a una visión representativa y liberal de la democracia.

\section{Las RS de la Participación}

Mediante la técnica de asociación de palabras se obtuvieron 58. Para estudiar la estructura de la RS, las palabras fueron agrupadas según su relación con los distintos modelos de participación (Tabla 4). Por lo cual, el corpus textual se redujo a un total de 33. Las palabras que fueron difíciles de relacionar en algún modelo de participación y ciudadanía, por su carácter general y ambiguo, se agruparon según las otras palabras que vincularon los estudiantes con el concepto de participación y 2 palabras (docentes y empeño) no se pudieron agrupar.

Tabla 4. RS y Modelos de participación: ¿Qué palabras asocian?

\begin{tabular}{|c|c|c|c|c|}
\hline Características & Liberal & Republicano & Comunitarista & Radical \\
\hline $\begin{array}{l}\text { ¿Qué palabras } \\
\text { asocian con la } \\
\text { participación? }\end{array}$ & $\begin{array}{l}\text { Un deber, respetar las } \\
\text { leyes, votar, elegir, } \\
\text { contactar políticos, } \\
\text { partidos políticos, } \\
\text { donar dinero (ayuda } \\
\text { asistencialista) }\end{array}$ & $\begin{array}{c}\text { Expresar opiniones y } \\
\text { posiciones, dialogar, } \\
\text { argumentar, razonar, } \\
\text { debatir, refutar, } \\
\text { conciliar, reflexionar, } \\
\text { discusión política, } \\
\text { ideas, propuestas }\end{array}$ & $\begin{array}{c}\text { Asociarse, } \\
\text { participar de } \\
\text { los asuntos } \\
\text { públicos directa } \\
\text { y activamente, } \\
\text { servicio, } \\
\text { cooperación, } \\
\text { trabajo en equipo }\end{array}$ & $\begin{array}{c}\text { Liderazgo, denunciar, } \\
\text { compromiso, } \\
\text { organizarse, } \\
\text { protestar, realizar } \\
\text { un boicot, un mitin, } \\
\text { una manifestación, } \\
\text { una huelga o una } \\
\text { movilización social, } \\
\text { cambio, intervenir. }\end{array}$ \\
\hline
\end{tabular}

Fuente: Elaboración propia.

Como lo muestra la Fig. 4, las palabras que aparecieron con mayor frecuencia están relacionadas con un modelo de participación liberal $(34,6 \%)$ y nos sorprendió el alto porcentaje relacionado con el modelo radical (32,7\%). Sin embargo, al desagregar la información, la palabra que tiene mayor frecuencia (5), entre las palabras que se asocian con una participación radical, es el término ayudar. Término que puede llegar a ser ambiguo, pues se puede mirar desde un carácter asistencialista (muy apegado a una participación liberal) o desde un carácter solidario y empático (muy apegado a una participación radical). De esta manera, haciendo un análisis de las respuestas de forma individual, evidenciamos que los estudiantes asocian el término ayudar junto a expresiones como opinar o votar, es decir, visiones de participación más republicanas y liberales que radicales.

Por otro lado, haciendo el análisis individual de las respuestas y observando la relación entre las palabras que asocian y los modelos de participación (Fig. 5), evidenciamos que, de 


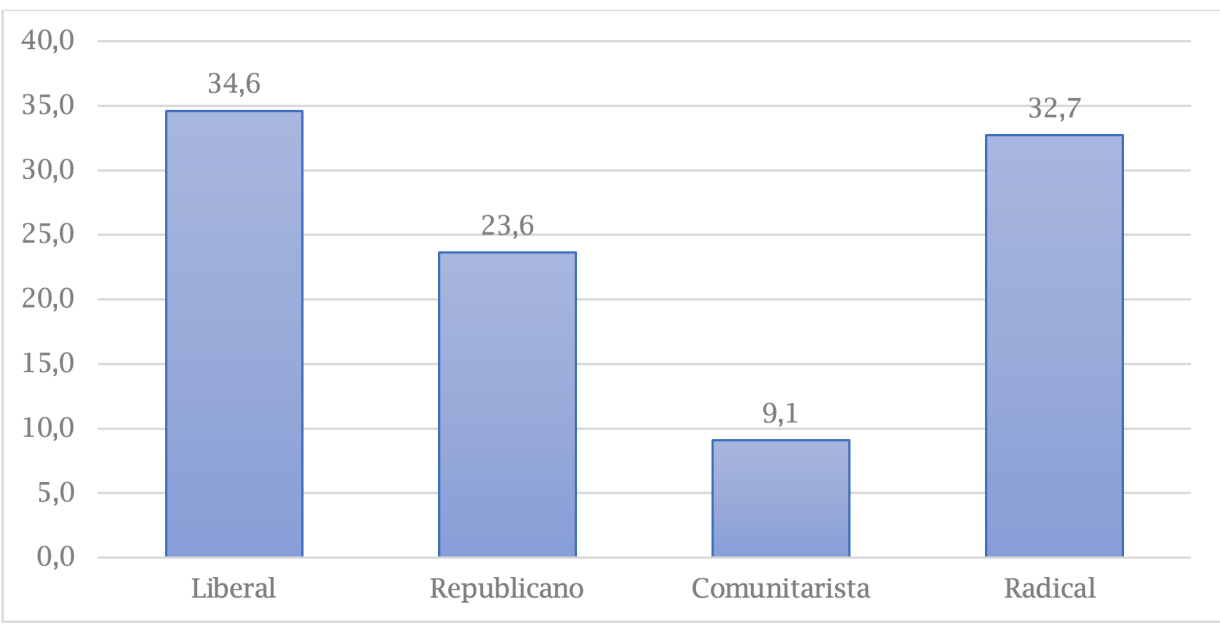

Fig. 4. Frecuencia de palabras según modelos de participación. Fuente: Elaboración propia.

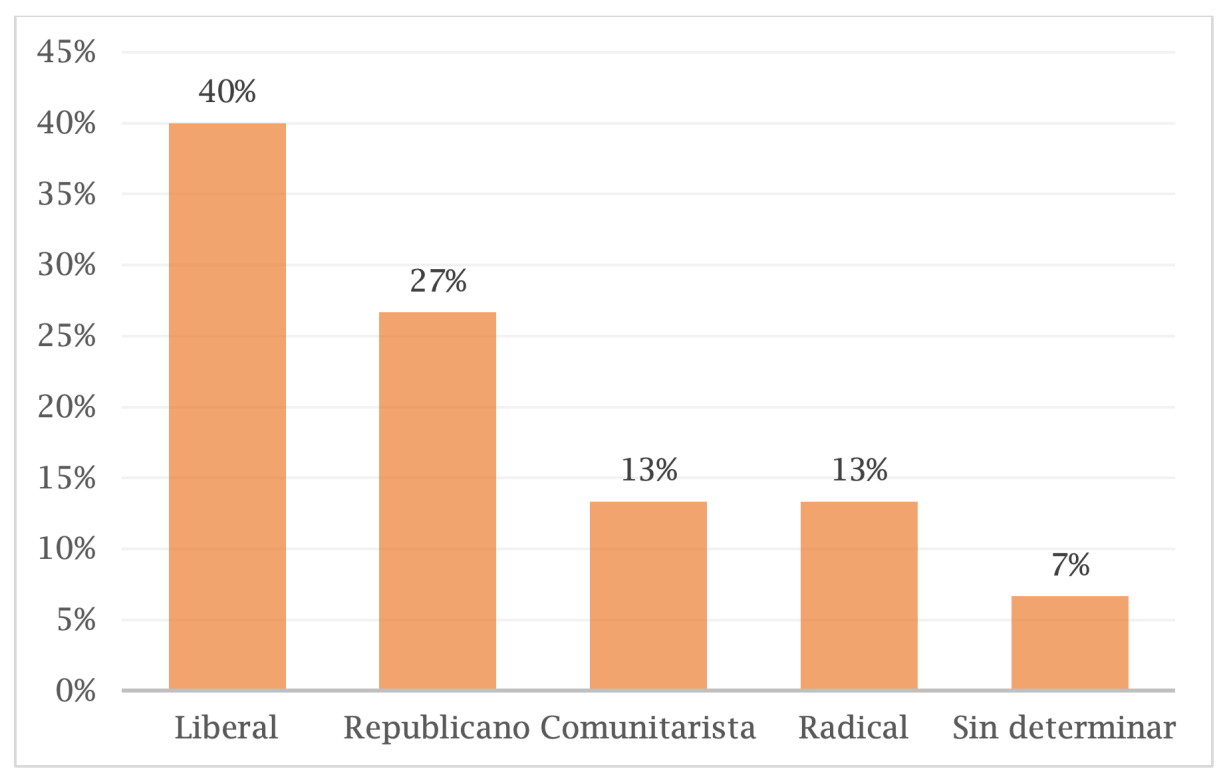

Fig. 5. Tipificación de estudiantes según el modelo de participación. Fuente: Elaboración propia.

los 15 estudiantes que respondieron el cuestionario, el 40\% se podría tipificar como liberal, $27 \%$ como republicano, el $13 \%$ como comunitarista o radical y un $7 \%$ no se puede tipificar por el carácter ambiguo y fuera de contexto de sus respuestas.

En cuanto a los términos con mayor frecuencia, estos fueron: sociedad, opinar y ayudar. Estas palabras aparecieron un total de 18 veces, es decir, son el 31\% del corpus textual. Por su parte, un total de 9 de los 15 estudiantes, es decir, el 63\% de los participantes, asoció, en primer lugar, palabras que se relacionan con una reunión o aglomeración de personas, tales como: organización social, pueblo, sociedad, personas, compañerismo y grupo de personas. Y con palabras que se relacionan con expresar opiniones, tales como: opinión del pueblo, opinión, opinar 
y libertad de expresión. Lo anterior nos sugirió que el Núcleo Central de la RS de la participación, para este grupo, está compuesto por aspectos como reunión, opinión y colaboración, por lo cual, podríamos deducir que los estudiantes representan la participación como un grupo de personas o de gente que se reúne para expresar sus opiniones y colaborar entre sí.

Este aspecto es importante, pues vemos cómo las RS de la participación en los estudiantes han ido avanzando desde una visión liberal, como mostraron los estudios descritos al inicio, hacia una visión republicana. Esto se evidencia al ver cómo las palabras voto y elecciones sólo tuvieron una frecuencia de 3 entre 58 palabras. Sin embargo, también es considerable el porcentaje de estudiantes que podemos tipificar como liberales, al hacer el análisis individual de sus respuestas.

Teniendo en cuenta los resultados de frecuencia, rango y tipificación de los estudiantes, evidenciamos que el principal contenido de sus RS de la participación está compuesto por aspectos asociados con los modelos de participación liberal y republicano.

\section{Las RS de la Ciudadanía}

Mediante la técnica de asociación de palabras se obtuvieron 66. Para estudiar la estructura de la RS, las palabras fueron agrupadas según su relación con los distintos modelos de ciudadanía (Tabla 5). Por lo cual, el corpus textual se redujo a un total de 19 (no todas las palabras de la Tabla 5 fueron asociadas). Las palabras que fueron difíciles de relacionar en algún modelo, por su carácter general y ambiguo, se agruparon según las otras palabras que vincularon los estudiantes con el concepto de ciudadanía.

Tabla 5. RS y Modelos de ciudadanía: ¿Qué palabras asocian?

\begin{tabular}{|c|c|c|c|c|}
\hline Características & Liberal & Republicano & Comunitarista & Radical \\
\hline $\begin{array}{c}\text { ¿Qué palabras } \\
\text { asocian con la } \\
\text { ciudadanía? }\end{array}$ & $\begin{array}{l}\text { Individuos, pasividad, } \\
\text { políticos, parlamento, } \\
\text { partidos políticos, } \\
\text { elecciones, voto, } \\
\text { deberes, derechos, } \\
\text { leyes, Estado, mayoría } \\
\text { de edad, Gobierno, } \\
\text { responsabilidad, } \\
\text { méritos, formas de } \\
\text { participación electoral }\end{array}$ & $\begin{array}{l}\text { Opinión, deliberación, } \\
\text { conciliación, } \\
\text { asambleas, } \\
\text { argumentos, razonar, } \\
\text { debatir, consensos, } \\
\text { participar de las } \\
\text { instituciones } \\
\text { sociales y políticas } \\
\text { estatales, formas } \\
\text { de participación } \\
\text { institucional }\end{array}$ & $\begin{array}{l}\text { Colectivo, lealtad, } \\
\text { pertenencia, } \\
\text { asociación, grupos, } \\
\text { minorías, identidad, } \\
\text { reconocimiento, } \\
\text { participación } \\
\text { comunitaria, } \\
\text { compromiso, } \\
\text { servicio, formas } \\
\text { de participación } \\
\text { comunitaria }\end{array}$ & $\begin{array}{l}\text { Oposición, conflicto, } \\
\text { desacuerdo, alteridad, } \\
\text { discordia, libertad, } \\
\text { movimientos sociales, } \\
\text { solidaridad, crítica, } \\
\text { manifestación, } \\
\text { movilización, } \\
\text { resistir, huelga, } \\
\text { protesta, mitin, lucha, } \\
\text { transformación, } \\
\text { formas de } \\
\text { participación radical }\end{array}$ \\
\hline
\end{tabular}

Fuente: Elaboración propia.

Como podemos verlo en la Fig. 6, las palabras que aparecieron con mayor frecuencia están relacionadas con una ciudadanía liberal (59\%). Los términos más comunes fueron: individuos, Estado, derechos y deberes. Por otro lado, los estudiantes también relacionaron la ciudadanía con la idea de colectivo de individuos, lo que se puede asociar con el concepto de ciudadanía comunitarista (21\%). En este grupo, los términos más comunes fueron: comunidad y pueblo. 


\section{F. Caballero et al.}

Las palabras que más asociaron con la ciudadanía fueron: personas, gente, sociedad, país, ciudad, derechos, deberes, comunidad y pueblo. Éstas aparecieron un total de 34 veces, es decir que son el 51\% del corpus textual y un total de 9 de los 15 estudiantes, es decir, el 63\% de los participantes, asoció en primer lugar este tipo de palabras con la ciudadanía. La palabra personas fue asociada en primer lugar por 4 de los 15 estudiantes. Lo anterior nos sugirió que el NC de la RS de la ciudadanía, para este grupo, está compuesto por aspectos como: individuos, comunidad, derechos y espacio, por lo cual, podríamos deducir que los estudiantes se representan a los ciudadanos como un grupo de personas o de gente que posee unos derechos y unos deberes y que se asientan o hacen parte de un determinado espacio.

Por otro lado, es considerable la frecuencia de palabras que los estudiantes asociaron y podemos identificar con la ciudadanía radical (17\%), algo que en principio no preveíamos (Fig. 6). Los términos asociados fueron: oposición, solidaridad y protesta. Sin embargo, al desagregar la información, todas las palabras de este tipo sólo tienen una frecuencia de 1 .

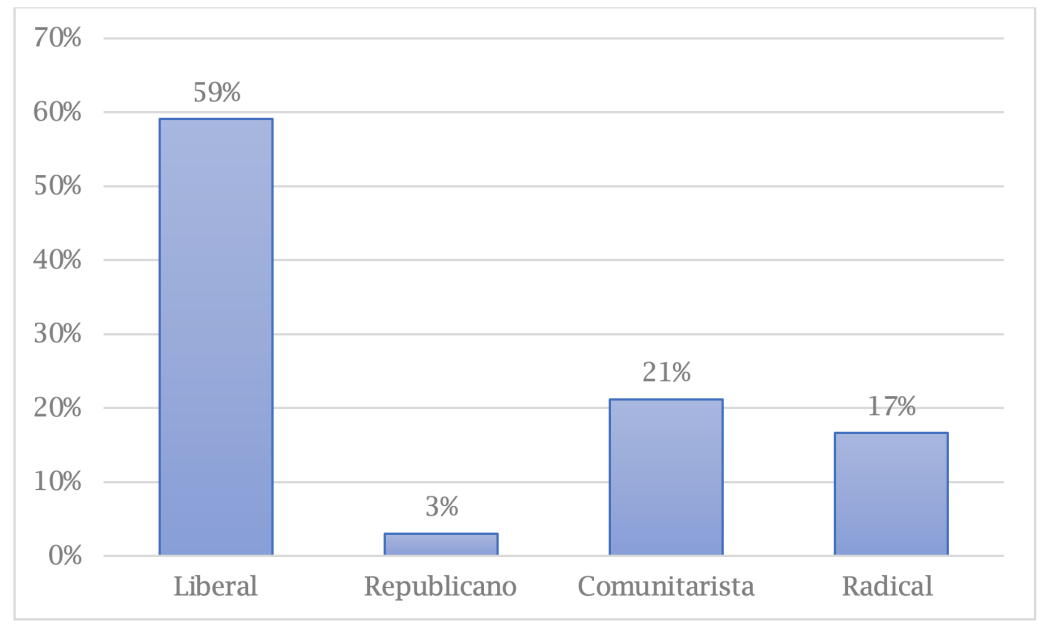

Fig. 6. Frecuencia de palabras según modelos de ciudadanía.

Fuente: Elaboración propia.

Teniendo en cuenta los resultados, evidenciamos que la principal característica y contenido de las RS de la ciudadanía de los estudiantes está compuesto por aspectos asociados, principalmente, con la ciudadanía liberal y una definición tradicional y hegemónica del ciudadano: como un individuo o grupo de personas que tienen y adquieren unos derechos y unos deberes en un territorio o espacio. También es importante reconocer que algunos estudiantes emplean palabras que se asocian con una ciudadanía radical.

\section{Las Formas de Participación}

Entre las acciones de participación que más han realizado los estudiantes, el mayor porcentaje corresponde a acciones de tipo liberal y republicano, situación que coincide con 
el contenido y el NC de sus RS. De esta manera, vemos cómo el 87\% de los estudiantes afirma que ha votado alguna vez, situación que se explica por el carácter de obligatoriedad que tiene, en las instituciones educativas, el proceso de elección de representantes estudiantiles, personeros y contralores (Fig. 7). Por su parte, el 67\% de los estudiantes afirma haber expresado sus opiniones, creencias y haber debatido y argumentado sus ideas en distintos espacios, hecho que se puede explicar con la asociación que hacen los estudiantes de la idea de expresar sus opiniones con la acción de participar en clases o por su participación en los consejos estudiantiles (Fig. 7).

Por otro lado, son alentadores los porcentajes que muestran acciones de participación que podemos considerar como radicales o comunitarias, pues, un $67 \%$ de los estudiantes afirma que ha propuesto acciones para resolver las problemáticas que los afectan y un $53 \%$ afirma que ha asistido, organizado o realizado una manifestación, concentración, movilización o huelga para expresar sus inconformidades y ha denunciado ante los entes de control las injusticias (Fig. 7). No obstante, teniendo en cuenta el contenido de las RS de los estudiantes, podemos sugerir que el hecho de que las personas hagan parte o realicen acciones no convencionales de participación, no quiere decir que tengan RS de la participación que correspondan a un modelo de ciudadanía y de participación crítico y radical, ya que determinadas acciones no se fundamentan en una reflexión sobre la necesidad del cambio social, sino en dinámicas grupales sin una justificación clara a nivel individual.

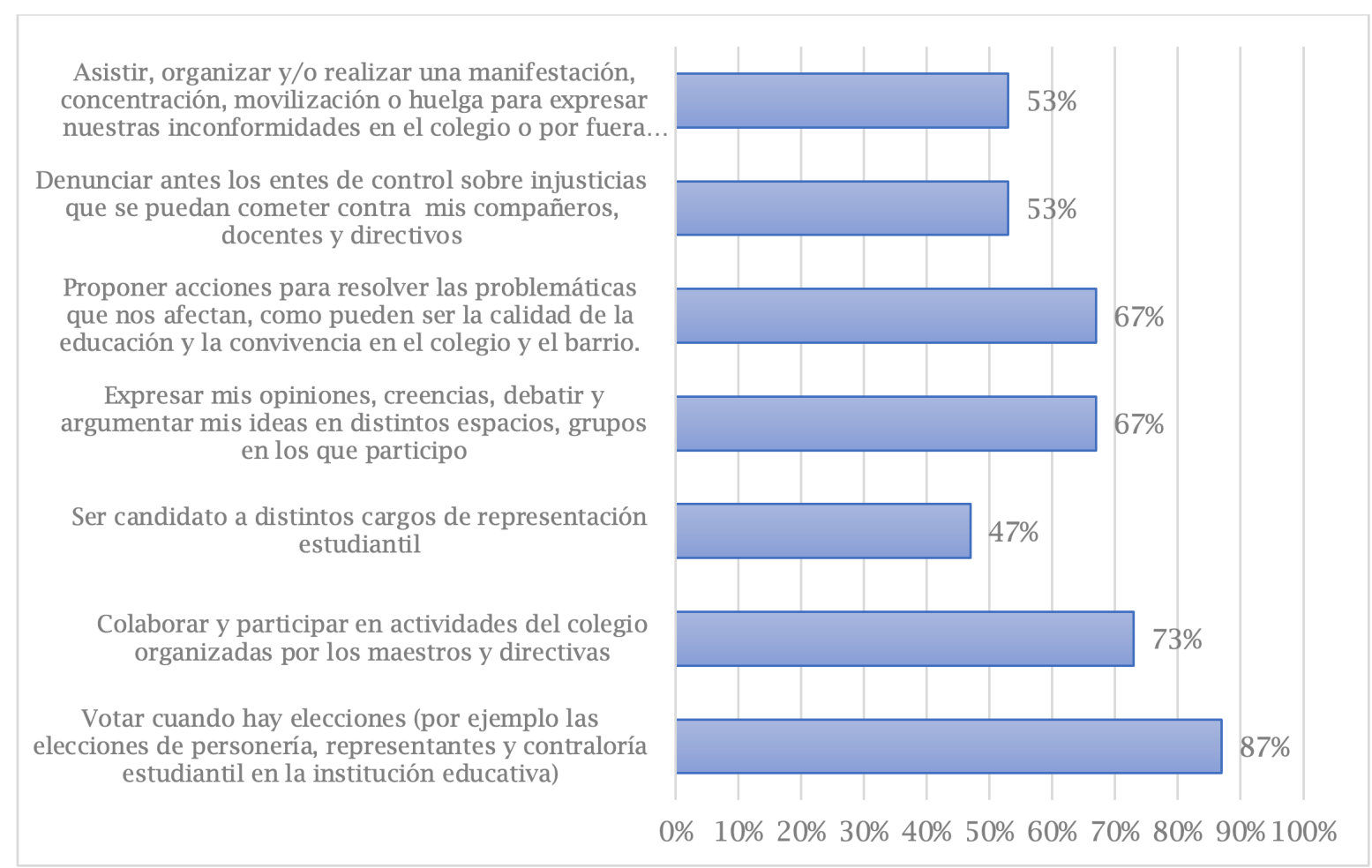

Fig. 7. Formas de participación.

Fuente: Elaboración propia. 


\section{F. CABallero et al.}

\section{La Enseñanza de la Participación en las clases de ciencias sociales}

Son bastante alentadoras las respuestas que dan los estudiantes a la pregunta: ¿Con qué relacionan los profesores la democracia, la participación y la ciudadanía en las clases de ciencias sociales? Pues, vemos que los docentes, en sus prácticas de enseñanza, relacionan estos términos con acciones de tipo republicano, radical y comunitarista y no sólo con modelos de participación liberal.

De esta forma, como lo muestra la Fig. 8 los estudiantes afirman que los docentes asumen la participación, la ciudadanía y la democracia desde nociones de argumentar ideas y opiniones (80\%), hablar y debatir sobre los problemas que afectan al país (87\%), los movimientos sociales (80\%) y la búsqueda de la transformación social (80\%). Sin embargo, también siguen siendo considerables las relaciones que hacen los docentes con acciones de tipo liberal y formas de educación cívica como la enseñanza de la constitución (80\%), la enseñanza del sistema de gobierno y enseñar a votar (80\%) y educar en buenos comportamientos y valores (80\%). Esto explica que el NC de las RS de los estudiantes se encuentre entre un modelo de política, democracia, participación y ciudadanía liberal y republicano, y que también puedan llegar a considerar y a realizar acciones cercanas a un modelo comunitarista y radical.

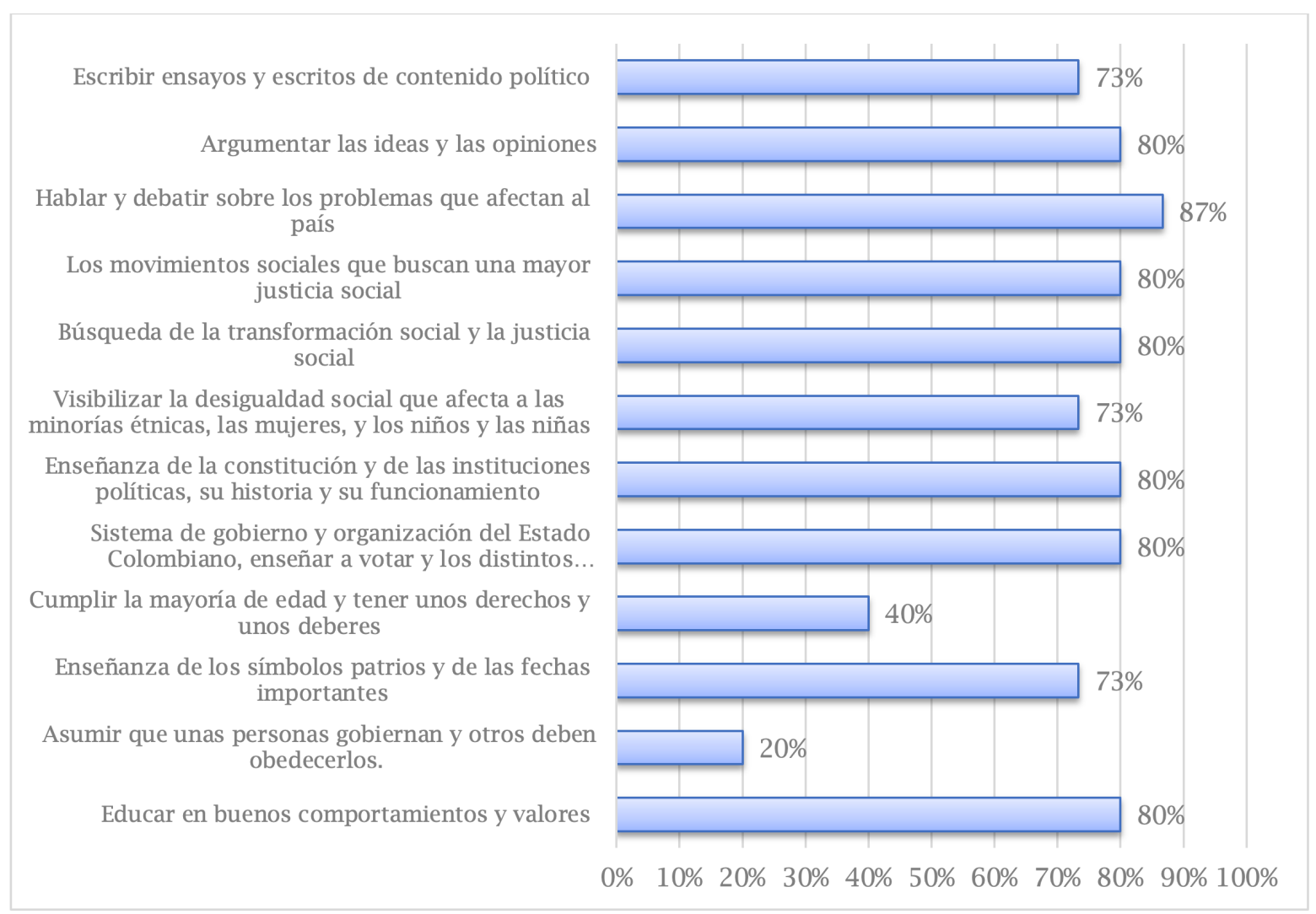

Fig. 8. Enseñanza de la participación en las clases de CS Fuente: Elaboración propia. 
Por otro lado, es interesante ver cómo los docentes han avanzado en la idea de que la ciudadanía no se corresponde, necesariamente, con la mayoría de edad (40\%) ni con asumir que unas personas gobiernan y otros obedecen (20\%), pues esto es una ventaja significativa para que se pueda avanzar en una educación en donde la participación se asocie con cambios sociales significativos.

\section{CONCLUSIONES}

Los datos muestran que la mayoría de los estudiantes asocian la ciudadanía, la democracia y la política con prácticas, expresiones y palabras del modelo de ciudadanía liberal y del sistema político representativo, mientras que asocian la participación con prácticas, expresiones y palabras del modelo de participación liberal y republicano. Por lo cual, consideramos que, aunque asuman la participación como la posibilidad de argumentar, debatir y expresar sus ideas y opiniones, aún tienen una significación tradicional y convencional de la ciudadanía, la política y la democracia, lo que quiere decir que no han tomado el grado de conciencia y de sentido crítico necesario para avanzar hacia una ciudadanía capaz de plantear transformaciones sociales a partir de su acción social.

Así, las RS de la política de los estudiantes están compuestas por aspectos como: políticos y corrupción, por lo cual, podríamos deducir que los estudiantes se representan a la política como un grupo de personas corruptas que se dedican a la política. Política que despierta sentimientos, emociones, opiniones y expresiones en su mayoría negativas y se asocia con la corrupción, la mentira y las injusticias.

Las RS de la democracia están compuestas por aspectos como: políticos y elecciones, por lo cual, podríamos deducir que los estudiantes se representan la democracia como un sistema o régimen político en el cual hay igualdad política y en donde el pueblo elige sus representantes y gobernantes de entre una élite política.

La participación la asocian los estudiantes a palabras como: reunión, opinión y colaboración, por lo cual, podríamos deducir que los estudiantes se representan la participación como un grupo de personas o de gente que se reúne para expresar sus opiniones y colaborar entre sí. Idea de participación que ha ido avanzando de una visión liberal hacia una visión republicana.

Las RS de la ciudadanía de los estudiantes se asocian, principalmente, con aspectos de la ciudadanía liberal y con una definición tradicional y hegemónica del ciudadano, representándose la ciudadanía como un individuo o grupo de personas que tienen y adquieren unos derechos y unos deberes en un territorio o espacio.

En cuanto a las formas de participación, el mayor porcentaje de acciones realizadas por los estudiantes son de tipo liberal y republicano: votar, expresar sus opiniones y creencias y debatir y argumentar sus ideas en distintos espacios. Acciones que se relacionan con las prácticas de enseñanza de los docentes, los cuales asocian la participación, la ciudadanía y la democracia con nociones como argumentar ideas y opiniones, hablar y debatir sobre los problemas que afectan al país, la enseñanza de la constitución, la enseñanza del sistema de gobierno, enseñar a votar y educar en buenos comportamientos y valores. 


\section{F. Caballero et al.}

Teniendo en cuenta estos resultados, creemos que sería necesario diseñar intervenciones didácticas que discutan y debatan dichas RS y modelo de ciudadanía, democracia, política y participación, para lograr que los estudiantes piensen en prácticas y formas de participación y de ejercer la ciudadanía que se relacionen con una ciudadanía crítica y radical.

De esta forma, para una propuesta de intervención didáctica en las clases de ciencias sociales pensamos que debemos profundizar en los contenidos y características centrales de las RS de la participación, la ciudadanía, la democracia y la política, ya que, al entender la forma en que los estudiantes estructuran y organizan sus representaciones y entendiendo cuál es su núcleo figurativo y las RS hegemónicas, podemos plantear preguntas, mostrar contradicciones o incoherencias en las maneras de pensar y sugerir posibilidades que no se hayan tenido en cuenta. Creemos que para poder generar cambios en las RS es necesario que las intervenciones didácticas generen momentos de crisis y conflicto de las representaciones sociales hegemónicas.

Para tal fin, consideramos importante trabajar con problemas sociales relevantes o cuestiones socialmente vivas (Evans \& Saxe, 1996; Legardez \& Simonneaux, 2011; Pagès \& Santisteban, 2011; Santisteban, 2017), que pongan en discusión las RS hegemónicas de nuestro alumnado, pues la transformación efectiva de una representación únicamente se realiza si el mismo NC es puesto en causa (Abric, 2011). Es necesario, de esta manera, mostrar a los estudiantes la realidad social, para:

... poner un rostro humano en temas como la guerra, la pobreza y la explotación, a nivel global o local, para avanzar hacia la solidaridad y hacia una democracia más activa y participativa en las escuelas (...) Hemos de incorporar a los y las invisibles en la enseñanza de las ciencias sociales, a las niñas, a los niños, a las mujeres, a los ancianos, a los enfermos, a las identidades diferentes, a culturas invisibilizadas (Santisteban, 2017, p. 560 y 562).

Los resultados de nuestras investigaciones nos llevan a pensar que las intervenciones didácticas deberían convertirse en un espacio de encuentro con la realidad social del país, que incluya los temas controvertidos, las injusticias y las desigualdades, y, a su vez, que enseñe a distinguir los futuros posibles, probables y deseables (Hicks, 2006; Anguera \& Santisteban, 2016), conscientes de la responsabilidad individual y colectiva en cada caso.

Creemos, entonces, que la clase debe convertirse en un espacio de encuentro, debate y cuestionamiento de aquello que parece permanente o inamovible, que permita la posibilidad de nuevas realidades y formas de ciudadanía, democracia, política y participación, desde la deconstrucción de las creencias, informaciones e ideas que el alumnado posee. Así, lo que estamos proponiendo es que las intervenciones didácticas se conviertan en la oportunidad de interpretación crítica de los discursos, las prácticas y las actitudes.

Consideramos que es importante formar a los estudiantes para la acción y el cambio social, brindándoles herramientas alternativas de participación ciudadana a través, por ejemplo, del estudio de los movimientos sociales, para que comprendan que hacer política va más allá de los partidos políticos y las instituciones políticas, porque hacer política quiere decir participar en todos los niveles de la sociedad, asumir responsabilidades y compromiso social 
con la mejora de las condiciones de vida, con los derechos humanos, con la justicia social.

Planteamos, como primer paso, que las intervenciones didácticas deben explorar el NC y el SP de las RS de la política, la participación, la ciudadanía y la democracia. Luego, proponemos que dichas RS hegemónicas deben ser puestas en crisis desde el estudio de problemas sociales relevantes o cuestiones socialmente vivas, como el único camino para el desarrollo de competencias de pensamiento crítico, de participación democrática y de aprendizaje de la acción social. Planteamos una enseñanza de las ciencias sociales y una educación para la ciudadanía como instrumento de análisis de la realidad y de transformación social.

Finalmente, somos conscientes que modificar el NC de las RS es un proceso lento que requiere de diversas estrategias y contextos de aprendizaje en el aula, y que no pueden modificarse con sólo una intervención didáctica. Sin embargo, consideramos que podemos y debemos incidir en las RS de nuestro alumnado, como meta esencial de la formación ciudadana (Pagès \& Oller, 2007). En nuestra investigación, hemos comprendido las posibilidades y el camino para deconstruir y reconstruir las representaciones del alumnado sobre la ciudadanía, la política y la participación, para repensar la democracia como el poder de las personas para mejorar la sociedad, desde el propósito ineludible en nuestra tarea docente de la justicia social.

\section{REFERENCIAS}

Abric, J. (2001). Las representaciones sociales: aspectos teóricos. En J.L. Abric (Ed.), Prácticas Sociales y Representaciones Sociales (pp. 11-32). México: Ediciones Coyoacán.

Abric, J. (2001a). Metodología de recolección de las representaciones sociales. En J.L. Abric (Ed.), Prácticas Sociales y Representaciones Sociales (pp. 53-74). México: Ediciones Coyoacán.

Alcaldía de Bogotá (2015). Condiciones sociales de los territorios de Suba. Recuperado de http:// www.gestionycalidad.org/infosuba/?bloque=contenido2\&id=70\&id_item $=73 \& i d$ _ menu=13\&name=9.Inf.\%20Sector\%20Integraci\%F3n\%20Social [13 de marzo de 2018]

Álvarez, A., \& Monedero, J. (2002). Gobiernos escolares, democracia representativa y las dificultades de la educación democrática. Recuperado de: https://docplayer. es/18305766-Gobiernos-escolares-democracia-representativa-y-las-dificultades-de-laeducacion-democratica.html [13 de noviembre de 2012]

Anguera, C., \& Santisteban, A. (2016). Images of The Future: Perspectives of Students from Barcelona. Journal of Futures Studies, 21(1), 1-18.

Araya, S. (2002). Las representaciones sociales: Ejes teóricos para su discusión. Cuaderno de Ciencias Sociales 127. Costa Rica: Facultad Latinoamericana de Ciencias Sociales (FLACSO).

Arendt, H. (1997). ¿Qué es la política? Barcelona: Paidós.

Benejam, P. (1997). Las finalidades de la educación social. En P. Benejam \& J. Pagès (Coords.), Enseñar y aprender Ciencias Sociales, Geografía e Historia (pp. 33-51). Barcelona: ICE Universidad de Barcelona / Horsori.

Benedicto, J. (2008). La juventud frente a la política: ¿desenganchada, escéptica, alternativa o las tres cosas a la vez? Revista de Estudios de Juventud, 81, 13-28. 


\section{F. Caballero et al.}

Bruno, D., \& Barreiro, A. (2015). La representación social de la democracia de adolescentes argentinos. Escritos de Psicología, 8(3), 33-40.http://doi.org/10.5231/psy.writ.2015.1506 Caballero, L. (2015). Del "no aprendí nada” al "hacerse escuchar". La construcción de subjetividades políticas y ciudadanas en una institución escolar de Bogotá. Nodos y Nudos, 4(38), 55-70.

Cerda, A., Loreto, M., Magendzo, A., Santa, E., \& Varas, R. (2004). El complejo camino de la formación ciudadana. Una mirada a las prácticas de los docentes. Santiago de Chile, Chile: LOM Ediciones.

Cortina, A. (1997). Ciudadanos del mundo. Hacia una teoría de la ciudadanía. Madrid: Alianza.

Cubides, H. (2000). Gobierno escolar y educación ciudadana. Estudio de Casos. Bogotá: Universidad Central-DIUC-Compensar.

De Alba, N., \& Navarro, E. (2016). ¿Qué concepción de la acción ciudadana tienen los jóvenes en España? declaraciones y propuestas. En C. García, A. Arroyo \& B. Andreu (Eds.), Deconstruir la alteridad desde la didáctica de las ciencias sociales: educar para una ciudadanía global (pp. 684-693). Las Palmas: Universidad de Las Palmas/AUPDCS.

Evans, R.W., \& Saxe, D.W. (1996). Handbook on Teaching Social Issues. Washington: NCSS.

González-Valencia, G. (2009). Qué significa para los profesores de ciencias sociales educar para la ciudadanía. Ideas desde Cataluña. En R.M. Ávila, B. Borghi \& I. Mattozzi (Coords.), L'educazione alla cittadinanza europea e la formazione degli insegnanti. Un progetto educativo per la "strategia di Lisbona” (pp. 69-76). Bologna: Pàtron Editore.

González-Valencia, G. (2012). La participación en la asignatura de Educación para la Ciudadanía. Una investigación sobre las representaciones sociales del profesorado. En N. De Alba, F. García, \& A. Santisteban (Eds.), Educar para la participación ciudadana en la enseñanza de las ciencias sociales. Vol. 2. (pp. 233-240). Sevilla: Díada / AUPDCS.

González-Valencia, G., \& Santisteban, A. (2016). La formación ciudadana en la educación obligatoria en Colombia: entre la tradición y la transformación. Revista Educación y Educadores, 19(1), 89-102.

Habermas, J. (1997). Historia y crítica de la opinión pública. La transformación estructural de la vida pública. Barcelona: Gustavo Gilli.

Herrera, M., Pinilla, A., Díaz, C., \& Infante, R. (2005). La construcción de cultura política en Colombia: proyectos hegemónicos y resistencias culturales. Bogotá: UPN.

Hicks, D. (2006). Lessons for the future. The Missing Dimensions in Education. Oxford: Trafford Publishing.

Horrach, J. (2009). Sobre el concepto de ciudadanía: Historia y modelos. Revista de Filosofía Factótum, 6, 1-22.

Jaime, A. (2008). Trayectorias de participación política de la juventud europea: ¿Efectos de cohorte o efectos de ciclo vital? Revista de Estudios de Juventud, 81, 67-93.

Jiménez, D. A. (2014). Lo público, la ciudadanía y los valores: reflexiones, tensiones y posibilidades. Magistro, 8(15), 181-202.

Jodelet, D. (1984). La representación social: Fenómenos, conceptos y teoría. En S. Moscovici (Comp.), Psicología Social II. Barcelona: Paidós.

Kymlicka, W., \& Norman, W. (1997). El retorno del ciudadano. Una revisión de la producción 
reciente en teoría de la ciudadanía en la política. La política: revista de estudios sobre Estado y la Sociedad (Ciudadanía: el debate contemporáneo), 3, 5-40.

Legardez, A. \& Simonneaux, L. (dir.) (2011). Education au développement durable et autres questions socialement vives. Dijon: Educagri.

Moscovici, S. (1961). El psicoanálisis, su imagen y su público. Buenos Aires: Huemul.

Mouffe, CH. (2007). En torno a lo político. Argentina: Fondo de la Cultura Económica (FCE).

Muñoz, C., Vásquez, N., \& Reyes, L. (2010). Percepción del estudiantado de enseñanza básica sobre el rol del Estado, las instituciones públicas, la democracia, la ciudadanía y los derechos de las mujeres y de los inmigrantes. Estudios Pedagógicos, 36(2), 153-175.

Pagès, J., \& Oller, M. (2007). Las representaciones sociales del derecho, la justicia y la ley de un grupo de adolescentes catalanes de $4^{\circ}$ de ESO. Enseñanza de las ciencias sociales: revista de investigación, 6, 3-19.

Pagès, J., \& Santisteban, A. (Coords.) (2011). Les qüestions socialment vives i l'ensenyament de les ciències socials. Barcelona: Publicacions de la UAB.

Peña, J. (2000). La ciudadanía hoy: problemas y propuestas. Valladolid: Universidad de Valladolid, Secretariado de Publicaciones e Intercambio Editorial.

Pinilla, A., \& Torres, J. (2006). De la educación para la democracia a la formación ciudadana, una década de incertidumbres. Bogotá: UPN - IDEP.

Ranciere, J. (2006). Política, policía, democracia. Santiago de Chile: LOM.

Rivera, A. (2016). Escollos y desafíos de la educación ciudadana en escuelas rurales del caribe colombiano. Una etnografía de escuela. Revista Iberoamericana de Educación, 71(2), 169-190.

Rodríguez, H., \& Contreras, C. (2014). Formación ciudadana: una apuesta desde la teoría crítica y la creación colectiva para la emergencia de subjetividades políticas en la infancia. Calle14, 9(14), 91-105.

Ross, E., \& Vinson, K. (2012). La educación para una ciudadanía peligrosa. Enseñanza de las Ciencias Sociales: Revista de investigación, 11, 73-86.

Salinas, J., \& Oller, M. (2017). Representaciones sociales de la participación ciudadana en alumnos chilenos al final de la primaria. En R. Martínez, R. García \& R. García (Eds.), Investigación didáctica de las ciencias sociales: retos, preguntas y líneas de investigación (pp. 761-772). Córdoba: Universidad de Córdoba/AUPDCS.

Sant, E., Casas, M., \& Pagès, J. (2011). Participar para aprender la democracia. Las representaciones sociales de jóvenes catalanes sobre la participación democrática. Recuperado de: https://aprendeenlinea.udea.edu.co/revistas/index.php/unip/article/ viewFile/11076/10173 [13 de junio de 2017]

Sant, E., \& Pagès, J. (2012). Los conocimientos históricos y actuales para el aprendizaje de la participación como base de una ciudadanía crítica y activa. En N. De Alba, F. García \& A. Santisteban (Eds.), Educar para la participación ciudadana en la enseñanza de las ciencias sociales (Vol. 1) (pp. 363-372). Sevilla: Díada / AUPDCS.

Santisteban, A. (2017). La investigación sobre la enseñanza de las ciencias sociales al servicio de la ciudadanía crítica y la justicia social. En R. Martínez, R. García \& R. García (Eds.), Investigación didáctica de las ciencias sociales: retos, preguntas y líneas de investigación 
L. F. Caballero et al.

(pp. 558-567). Córdoba: Universidad de Córdoba/AUPDCS.

Santisteban, A., \& Pagès, J. (2009). Una propuesta conceptual para la investigación en educación para la ciudadanía. Revista Educación y Pedagogía, 21(53), 15-31. 